\title{
Tracheal adenoid cystic carcinoma: A case report
}

\author{
Christine Costa, Patrícia Dionísio, Paula Monteiro, \\ José Rosal Gonçalves, Salvato Feijó
}

\begin{abstract}
Introduction: Adenoid cystic carcinoma is rare in the trachea and, due to slow growth, it can go unnoticed or be confused with other obstructive pathologies for months/years. Case Report: We report a case of a 31-year-old woman who complained of having productive cough, wheezing and dyspnea on exertion with a progressive evolution during months. Bronchial asthma was considered and an inhaled therapy was started. After one month, she denied a significant improvement with treatment, referring inspiratory stridor. Chest X-ray showed a reduction of tracheal diameter in its distal portion and bronchoscopy revealed an extensive mass on the thoracic trachea, reducing the lumen by $80 \%$. Laser therapy for mass resection was performed, leading to recovery of tracheal permeability. Pathological examination revealed to be consistent with adenoid cystic carcinoma. After endoscopic treatment, the patient immediately noticed a relief of symptoms. Conclusion: Due to the extension of
\end{abstract}

Christine Costa ${ }^{1}$, Patrícia Dionísio ${ }^{1}$, Paula Monteiro² ${ }^{2}$ José Rosal Gonçalves ${ }^{3}$, Salvato Feijó ${ }^{4}$

Affiliations: ${ }^{1}$ Resident, Chest Department, Centro Hospitalar Lisboa Norte, Lisbon, Portugal; ${ }^{2}$ Pulmonary Specialist, Chest Department, Centro Hospitalar Lisboa Norte, Lisbon, Portugal; ${ }^{3}$ Chief of the Bronchology Unit, Chest Department, Centro Hospitalar Lisboa Norte, Lisbon, Portugal; ${ }^{4}$ Chief of Department, Pulmonology Department, Cento Hospitalar de Leiria, Leiria, Portugal.

Corresponding Author: Christine Costa, Av. Prof. Egas Moniz, 1649-035 Lisboa, Portugal; Email: christinesilvacosta@gmail.com

Received: 26 November 2017

Accepted: 27 December 2017

Published: 01 February 2018 tumor at the time of diagnosis, adenoid cystic carcinomas are frequently unresectable. In these cases, radiotherapy and/or chemotherapy are suggested. In cases of severe tracheal obstruction, bronchoscopic resection should be performed in order to immediate recovery of tracheal lumen permeability.

Keywords: Adenoid cystic carcinoma, Trachea, Treatment

\section{How to cite this article}

Costa C, Dionísio P, Monteiro P, Gonçalves JR, Feijó S. Tracheal adenoid cystic carcinoma: A case report. Int $\mathrm{J}$ Case Rep Images 2018;9:100883Zo1CC2018.

Article ID: 100883Zo1CC2018

$$
* * * * * * * * *
$$

doi: 10.5348/100883Zo1CC2018CR

\section{INTRODUCTION}

Primary tumors of the trachea are rare ( $<2 \%$ of tumors in the bronchial tree), and $40 \%$ are due to adenoid cystic carcinoma [1]. Adenoid cystic carcinoma (ACC) of the trachea affects men and women equally [2] from the 3 rd to 9th decades of life with the mean in the $5^{\text {th }}$ decade $[1,3]$. However, a case in a 14-year-old girl has been reported [4]. Predisposing factors are not known [1, 3] and there is apparently no association between tobacco and adenoid cystic carcinoma [4]. Due to slow growth [1], initial symptoms can be subtle and go unnoticed or be confused with other obstructive pathologies, such as asthma or chronic obstructive pulmonary disease [1-3, $5-7]$. 


\section{EDORIUM Journals}

\section{CASE REPORT}

A 31-year-old woman, non-smoker, with no relevant personal history, complained of having productive cough, wheezing and dyspnea on exertion with a progressive evolution during her third trimester of pregnancy. She was observed at the emergency room, where a summary analytical study was conducted, revealing no alteration, as well as a chest radiography. Clinical presentation was considered to be linked to pregnancy and she was later discharged. One month after delivery, due to persistence of symptoms, she was observed in a pulmonology consultation where bronchial asthma was considered. For this reason, she started empirical treatment with inhaled corticoid plus bronchodilator, and supplementary diagnostic tests were ordered. In the reassessment, the patient denied a significant improvement, referring inspiratory stridor. The chest X-ray showed a reduction of tracheal diameter in its distal portion (Figure 1), so bronchofibroscopy (BFC) was performed which revealed an extensive mammillated mass on the anterior and left lateral walls of the thoracic trachea, reducing the lumen by $80 \%$ and infiltrating the carina and left main bronchus (Figure 2A). A rigid bronchoscopy with laser therapy for mass resection was immediately performed, leading to recovery of tracheal permeability (Figure 2B). After the procedure, a relief of symptoms was immediately noticed. Pathological examination of the resected specimen was consistent with ACC. After the anatomopathological result, computed tomography of the neck, chest and abdomen was performed which demonstrated asymmetric parietal thickening of the tracheal wall from the thoracic operculum to its bifurcation, with extension to the left main bronchus, contacting adjacent mediastinal structures, and no clear signs of invasion (Figure 2C). Due to its extension, surgical resection was not possible, so she was referred to our pulmonary oncology unit to further treatment and follow-up.

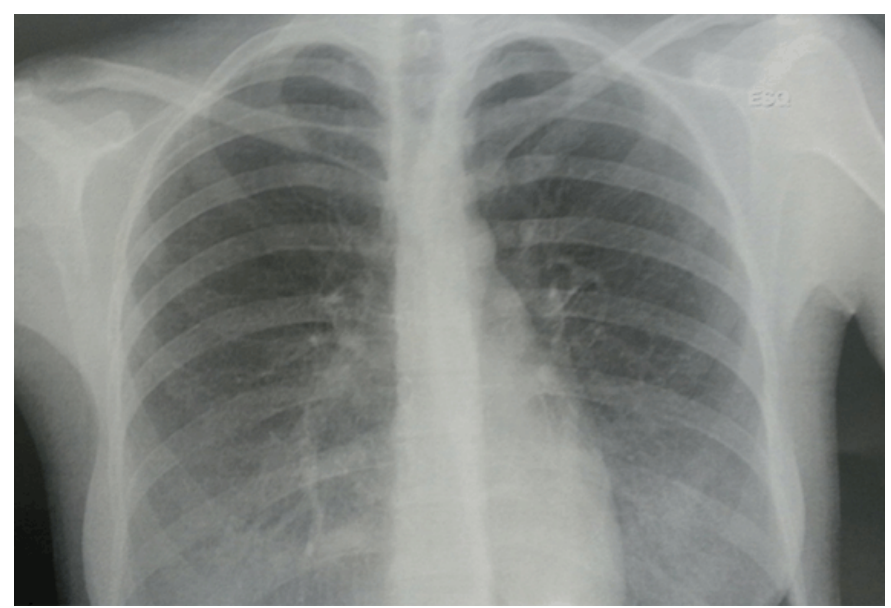

Figure 1: Chest X-ray demonstrating reduction of tracheal diameter in its distal portion.
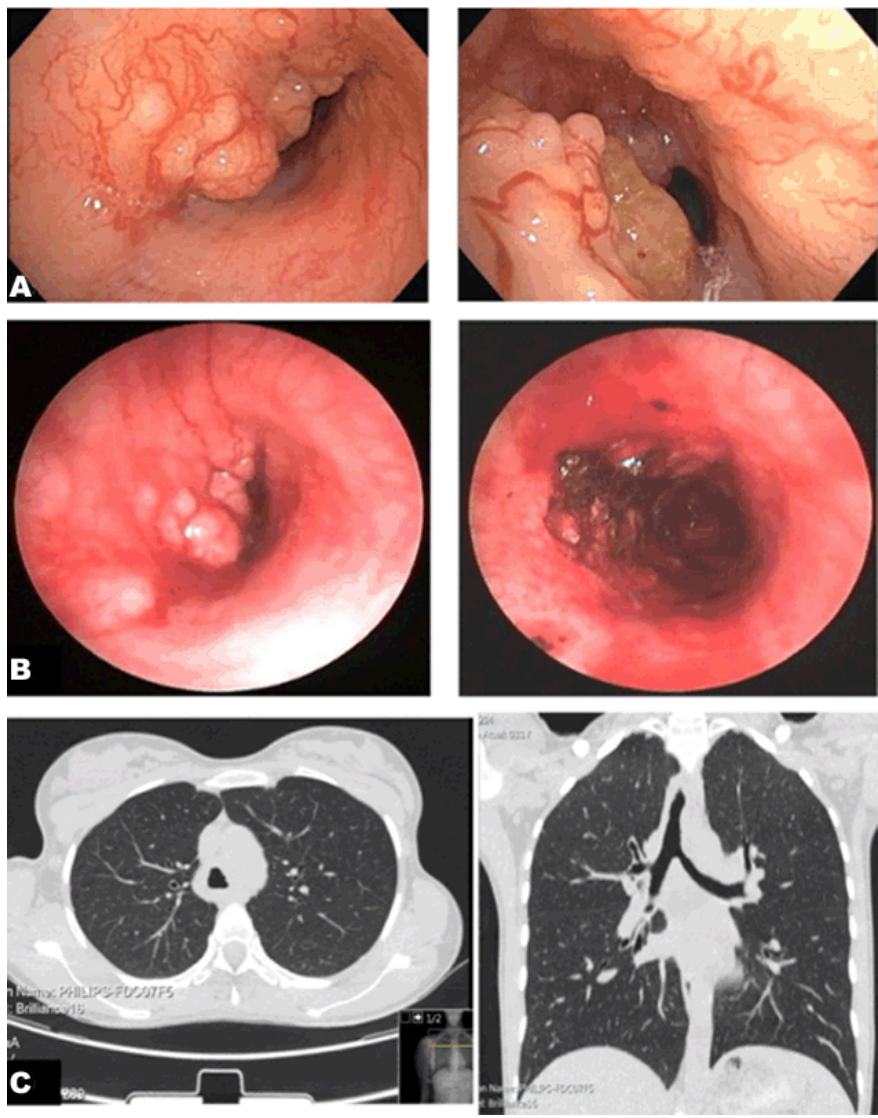

Figure 2: (A) Bronchofibroscopy images: tracheal mass causing about $80 \%$ of luminal obstruction, (B) Rigid bronchoscopy image in which the tracheal mass is seen (left) and after laser therapy, with recovery of tracheal lumen permeability (right), (C) Computed tomography images of the chest after laser therapy demonstrating thickening of the tracheal wall.

\section{DISCUSSION}

Adenoid cystic carcinoma of the trachea is relatively rare and tends to occur at younger ages than other neoplasms of the bronchial tree $[1,3,4]$. At the time of the diagnosis, patients usually present with inspiratory stridor, dyspnea, productive cough $[1,3,4,6]$ or, less frequently, hemoptysis $\left[3,5^{-7}\right]$. As dyspnea is generally the initial symptom, it is frequently confused with bronchial asthma, which can cause a delay in diagnosis. Further diagnostic examination consists of chest X-ray, which can either show latero-tracheal opacity or be normal, since tracheal tumors do not involve the lung parenchyma [1, 7]. Computed tomography scan provides valuable information on resectability by identifying loco regional involvement and extension of the lesion. Bronchoscopy is mandatory, as it allows not only the collection of material for confirmation of diagnosis, but also enables localization of the lesion and evaluation of its extension [1]. 


\section{EDORIUM Journals}

There are three possibilities of treatment:

- $\quad$ Surgery

- Radiotherapy and/or chemotherapy

- Interventional bronchoscopy [8].

Surgery with tracheal resection and termino-terminal anastomosis followed by adjuvant radiotherapy is the treatment of choice and can be followed by adjuvant radiotherapy $[1,3]$. However, apart from requiring an experienced team, surgery requires the lesion to be smaller than half the tracheal length $(<6 \mathrm{~cm})$ [1], and due to late diagnosis, with greater extension of the neoplastic lesion, this approach is often impossible. In unresectable cases, radiotherapy with a dose of 66-70 Gy should be considered [1]. Although there is not much information about late effects after definitive radiotherapy in ACC, high-dose thoracic radiotherapy has been associated with a risk of bronchial damage, such as narrowed airway [2]. Over the past few years, some cases of chemotherapy treatment with carboplatin and paclitaxel have been reported [8, 9], but results are still controversial [2, 6, 7]. In patients with severe obstruction, endoscopic resection using the Nd-YAG laser allows quick disobliteration, a procedure that can be repeated as many times as necessary [5].

Adenoid cystic carcinoma spreads most commonly by direct extension, submucosal or perineural invasion, or hematogenous metastasis $[2,3,5,6]$. Pulmonary metastases are the most common $[2,3]$ but metastases to the brain, bone, liver, kidney, skin, abdomen, and heart have also been reported [2]. Local recurrence of tracheal ACC is common and occurs at an average of 51 months after the primary treatment [2]. The 5 and 10 years overall survival rate is $52-91 \%$ and $29-76 \%$, respectively [6].

\section{CONCLUSION}

This is one of the rare case reports of ACC whose symptoms began during the pregnancy. As we reported in this case, endoscopic laser resection should be performed in cases of severe tracheal obstruction, in order to immediately achieve total or partial recovery of tracheal lumen permeability.

\section{REFERENCES}

1. Le Péchoux C, Baldeyrou P, Ferreira I, Mahé M, Péchoux C. Cylindromes thoraciques: Thoracic adenoid cystic carcinomas. Cancer/Radiothérapie 2016;9(6-7):358-61.

2. Yang PY, Liu MS, Chen CH, Lin CM, Tsao TC. Adenoid cystic carcinoma of the trachea: A report of seven cases and literature review. Chang Gung Med J 2005 May;28(5):357-63.

3. Huston B, Froloff V, Mills K, McGee M. Adenoid cystic carcinoma of the trachea resulting in fatal asphyxia. $J$ Forensic Sci 2017 Jan;62(1):244-6.
4. Masih I, Porter G, Porter S, et al. Primary adenoid cystic carcinoma of the bronchus in a female teenager. BMJ Case Rep 2010 Nov 29;2010. pii: bcro820103252.

5. Clough A, Clarke P. Adenoid cystic carcinoma of the trachea: A long-term problem. ANZ J Surg 2006 Aug;76(8):751-3.

6. Huo Z, Meng Y, Wu H, et al. Adenoid cystic carcinoma of the tracheobronchial tree: Clinicopathologic and immunohistochemical studies of 21 cases. nt J Clin Exp Pathol 2014 Oct 15;7(11):7527-35.

7. Bonner Millar LP, Stripp D, Cooper JD, Both S, James $\mathrm{P}$, Rengan R. Definitive radiotherapy for unresected adenoid cystic carcinoma of the trachea. Chest 2012 May;141(5):1323-6.

8. Suzuki T. What is the best management strategy for adenoid cystic carcinoma of the trachea? Ann Thorac Cardiovasc Surg 2011;17(6):535-8.

9. Allen AM, Rabin MS, Reilly JJ, Mentzer SJ. Unresectable adenoid cystic carcinoma of the trachea treated with chemoradiation. J Clin Oncol 2007 Dec 1;25(34):5521-3.

$* * * * * * * * *$

\section{Author Contributions}

Christine Costa - Substantial contributions to conception and design, Acquisition of data, Acquisition of data, Analysis and interpretation of data, Drafting the article, Revising it critically for important intellectual content, Final approval of the version to be published

Patrícia Dionísio - Acquisition of data, Analysis and interpretation of data, Drafting the article, Revising it critically for important intellectual content, Final approval of the version to be published

Paula Monteiro - Analysis and interpretation of data, Revising it critically for important intellectual content, Final approval of the version to be published

José Rosal Gonçalves - Analysis and interpretation of data, Revising it critically for important intellectual content, Final approval of the version to be published

Salvato Feijó - Acquisition of data, Analysis and interpretation of data, Drafting the article, Revising it critically for important intellectual content, Final approval of the version to be published

\section{Guarantor of Submission}

The corresponding author is the guarantor of submission.

\section{Source of Support}

None

\section{Consent Statement}

Written informed consent was obtained from the patient for publication of this case report.

\section{Conflict of Interest}

Authors declare no conflict of interest. 


\section{EDORiUM Journals}

\section{Copyright}

(C) 2018 Christine Costa et al. This article is distributed under the terms of Creative Commons Attribution License which permits unrestricted use, distribution and reproduction in any medium provided the original author(s) and original publisher are properly credited. Please see the copyright policy on the journal website for more information.
Access full text article on other devices

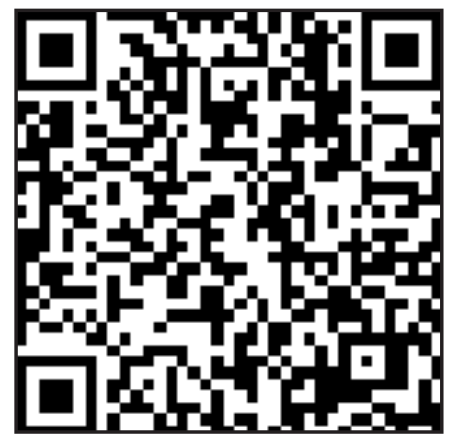

Access PDF of article on other devices

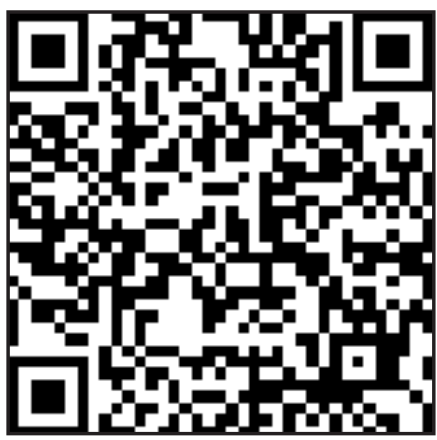

